\title{
Preliminary antimycobacterial study on selected Turkish plants (Lamiaceae) against Mycobacterium tuberculosis and search for some phenolic constituents
}

\author{
Tülin Askun ${ }^{1}$, Emmanuel Mouafo Tekwu ${ }^{1,2^{*}}$, Fatih Satil ${ }^{1}$, Seyma Modanlioglu' ${ }^{1}$ and Hatice Aydeniz ${ }^{1}$
}

\begin{abstract}
Background: The global resurgence of tuberculosis is a significant threat. Lamiaceae members have been used in folk remedies for centuries. This study was designed to assess the in-vitro antimycobacterial activity of eighteen crude extracts from six plants (Lamiaceae) and to characterize their phenolic and flavonoid compounds.

Methods: Six Turkish medicinal plants of the family Lamiaceae (Stachys tmolea Boiss., Stachys thirkei C. Koch, Ballota acetabulosa (L.) Benth., Thymus sipthorpii Benth., Satureja aintabensis P.H. Davis, and Micromeria juliana (L.) Benth. ex Reich.) were collected in 2009 - 2010. Dried and crushed plant samples were subjected to sequential extraction with petroleum ether, ethyl acetate, and methanol in order of increasing polarity. A broth microdilution method was employed to screen extracts against four mycobacterial strains of Mycobacterium tuberculosis. Phenolic and flavonoid compounds were characterized by liquid chromatography-mass spectrometry.
\end{abstract}

Results: S. aintabensis, T. sibthorpii, and M. juliana were found to develop considerable activity against the four strains of M. tuberculosis with the minimal inhibitory concentrations value of $12.5-100 \mu \mathrm{g} / \mathrm{ml}$. S. aintabensis and T. sibthorpii extracts killed M. tuberculosis with the minimum bactericidal concentration value of $50-800 \mu \mathrm{g} / \mathrm{ml}$. On the basis of these prominent antimycobacterial activity, we suggest that they could be a source of natural anti-tuberculosis agents.

Conclusion: S. aintabensis and T. sibthorpii showed activity by killing Mycobacteria strains. The major phenolic compound was rosmarinic for T. sibthorpii and S. aintabensis. Flavonoids might be "a modal" for the drug design.

Keywords: Mycobacterium tuberculosis, Antimycobacterial activity, Satureja aintabensis, Thymus sipthorpii,Lamiaceae, Phenolic, Flavonoid

\section{Background}

Tuberculosis (TB) is an infectious bacterial disease caused by Mycobacterium tuberculosis, which most commonly affects the lungs. It is a well-known disease that has afflicted humans since ancient times. Although tremendous efforts have been made to control TB at global and national levels, approximately one third of the world's population is infected with $M$. tuberculosis, eight million

\footnotetext{
* Correspondence: etekwu@yahoo.fr

'Department of Biology, Faculty of Sciences and Arts, University of Balikesir, Cagis Campus, Balikesir 10145, Turkey

²Laboratory for Tuberculosis Research (LTR), Biotechnology Centre, University of Yaoundé I, P.O. Box 8936, Yaoundé, Cameroon
}

people develop tuberculosis disease annually, while two million people die and another three million new cases occur each year [1]. The global resurgence of TB and the development of drug resistance, multidrug-resistant (MDR) and extensively drug resistant (XDR) strains present significant threats to TB control. The alarming increase of MDR$\mathrm{TB}$ cases requires the urgent development of new, more effective and safer anti-tuberculosis (anti-TB) drugs.

Lamiaceae members have been used as tea, spice or in folk remedies for centuries. The plant family Lamiaceae has a global distribution, and comprises more than 7200 species across approximately 240 genera [2]. Turkey is regarded as an important gene-center for the plant family 
Lamiaceae (Labiatae) [3]. The family has 256 species endemic to Turkey, and the rate of endemism in the family is $44.2 \%$ [ 3 ].

Stachys $L$. is one of the largest genera of the family Lamiaceae, and is used in herbal remedies and is consumed as a tea in Anatolia and Iran. Decoctions or infusions of Stachys are applied as tonics to treat skin complaints, or taken internally for stomach disorders [4]. The antibacterial [5], anticancer [6] and antioxidant effects [7] of the genus are described in the literature. The genus Thymus (Lamiaceae) has numerous species and varieties and the ratio of endemism in the genus is 53\% in Turkey [3]. Thymus oil is widely used as an antiseptic agent in many pharmaceutical preparations and as a flavoring agent for many kinds of food products [8]. In Turkey the genus Ballota is represented by eleven species and six subspecies, of which ten which are endemic [9]. Ballota species have been used in the treatment of wounds and burns, gastrointestinal disorders, as diuretics, in the treatment of hemorrhoids as infusions, as a choleretic and to prevent coughs in Turkish folk medicine [10].

M. juliana has several medicinal uses, such as preventing diabetes, tonsillitis, dyspepsia, stomach ulcers, lowering cholesterol, as an anti-spasmodic and preventing bronchitis, common cold, dysmenorrhea, prostate problems and kidney stones [11].

Many members of the genus Satureja are well known for their aromatic and medicinal character. They are used as culinary herbs and in folk medicine to treat various ailments, based on their different plant activities. The essential oil isolated from various Satureja species possesses certain biological properties, such as antifungal [12], antibacterial [13], anticholinesterase and antioxidant [14], and anti-HIV-1 [15] properties.

Medicinal plants have long been used in traditional healthcare systems to cure various ailments including tuberculosis [16]. Natural plant products have provided an alternative source for the development of antimicrobial drugs [17].

Flavonoids have been recognized as having several biological properties such as being anti-oxidant, anti-allergic and anti-infectious. Some flavonoids show antiviral and antibacterial activities such as quercetin, which is an HIV1-protease inhibitor [18]. Myricetin is also shown to inhibit the growth of vancomycin-resistant enterococci [19].

Numerous examples of interesting secondary metabolites with antimicrobial activity have been isolated from natural sources, indicating that natural products could be a useful field for the discovery of new anti-TB leads. The antimycobacterial properties of medicinal plants are increasingly being reported from different parts of the world, and antimycobacterial activities of members of the Lamiaceae family have been reported by some authors $[20,21]$.
In this study, six plants of the Lamiaceae family (Stachys tmolea Boiss., Stachys thirkei C. Koch, Ballota acetabulosa (L.) Benth., Thymus sipthorpii Benth., Satureja aintabensis P.H. Davis and Micromeria juliana (L.) Benth. ex Reich.) were investigated with traditional claims for several diseases. The objective of the present study was to evaluate the antimycobacterial activities and determine the phenolic composition of S. tmolea, S. thirkei, B. acetabulosa, T. siptorpii, S. aintabensis, and M. juliana. To the best of our knowledge, these six plants had not previously been screened for their activity against $M$. tuberculosis.

\section{Methods}

\section{Plant materials}

Six Turkish medicinal plants of the family Lamiaceae (S. tmolea, S. thirkei, B. acetabulosa, T. sibthorpii, S. aintabensis and $M$. juliana) were selected for their antimycobacterial activities. All the plant materials were further identified in the Department of Biology, University of Balikesir-Turkey, by Professor Gulendam Tumen. Voucher specimens were deposited at the Herbarium of Balikesir University, Department of Biology. The details herbarium data about plants were given with their locality, altitude, collection time, acquisition code numbers are listed in Table 1.

\section{Preparation of extracts}

The dried aerial parts of each plant (six plants) were cut into small pieces, weighed and subjected to a sequential extraction with different solvents according to their increasing polarity: petroleum ether, ethyl acetate, and methanol. For each sample, the plant material and respective solvents were left to macerate for two weeks at room temperature. The extracts were filtered through Whatman's No. 1 filter paper. The residue was re-extracted successively with the different solvents mentioned. Solvents were evaporated under reduced pressure using a rotavapor (Heidolph). Therefore, three fraction extracts of petroleum ether fraction (PEF), ethyl acetate fraction (EAF) and methanol fraction (MEF) were obtained for each herb. The total extraction yield, expressed as a percentage, is given in Table 2. Dry fractions were stored in a deepfreeze at $-20^{\circ} \mathrm{C}$ until use.

\section{Liquid chromatography-mass spectrometry analysis Chemicals and samples}

Gradient grade $\mathrm{MeOH}$ and acetonitrile were purchased from Merck. Gradient grade water $(18 \mathrm{~m})$ was prepared by using a Purelab Option-Q elga dv 25 system. All standard stock solutions $(1 \mathrm{mg} / \mathrm{ml})$ were prepared by dissolving each compound in $\mathrm{MeOH}$. Standards, rosmarinic acid, trans-cinnamic acid, and ferulic acid were purchased from Aldrich, caffeic acid and gallic acid from Sigma-Aldrich and all other chemicals used were obtained from Sigma. 
Table 1 Plant herbarium data according to locality, altitude, collection time, and herbarium number

\begin{tabular}{llllll}
\hline Plant no & Plant species & Locality & Altitude & Collection time & Herbarium number \\
\hline 1 & Stachys tmolea Boiss. & Balikesir, Edremit, Kazdagi National Park & $1400 \mathrm{~m}$ & 11 June 2010 & FS1550 \\
2 & Stachys thirkei C. Koch. & Sakarya, Akyazl, Davlumbaz plateau & $1300 \mathrm{~m}$ & 13 June 2010 & FS1551 \\
3 & Ballota acetabulosa (L.) Benth & Balikesir Gomec, Madra & $300 \mathrm{~m}$ & 3 June 2010 & FS1552 \\
4 & Thymus sibthorpii Benth. & Tekirdag & $1500 \mathrm{~m}$ & 20 June 2009 & FS1553 \\
5 & Satureja aintabensis P.H. Davis & Gaziantep, Duluk Forest & $850 \mathrm{~m}$ & 15 July 2009 & FS1554 \\
6 & Micromeria juliana (L.) Benth. ex Reich & Balikesir Edremit, Kazdagi & $450 \mathrm{~m}$ & 6 August 2009 & FS1555 \\
\hline
\end{tabular}

All solutions were passed through a membrane filter (Sartorius, $\varnothing 0.22 \mu \mathrm{m}$.) before injection into the capillary.

\section{Liquid chromatography-mass spectrometry conditions}

Analyses were performed with an Agilent Liquid chromatography-mass spectrometry (LC-MS) system (1200 LC with a single quadrupole) with Electrospray Ionisation (ESI) source-negative mode. Source parameters were optimized to provide highest sensitivity. The source parameters are: Gas temperature $350^{\circ} \mathrm{C}$, drying gas flow 12 $\mathrm{l} / \mathrm{min}$, nebulizer pressure $50 \mathrm{psi}$, capillary voltage $3500 \mathrm{~V}$.
Separation was carried by a Poroshell 120 SB-C18 column $(2.1 \times 100 \mathrm{~mm} 2.7 \mathrm{um})$. Mobile phases are A: Water (10 $\mathrm{mM}$ Ammonium Acetate $+0.2 \%$ Formic Acid) and B (100\% Methanol). The gradient program is: Start with $10 \%$ $\mathrm{B}$ and hold $0.2 \mathrm{~min}$; then increased to $30 \% \mathrm{~B}$ until $3 \mathrm{~min}$; increase B to $80 \%$ until $20 \mathrm{~min}$; increase B to $95 \%$ at 20.1 min and hold 2 min; decrease B to $10 \%$. Total run time is $35 \mathrm{~min}$. Injection volume is $5 \mu \mathrm{l}$. The detection was accomplished using MS SIM mode. Scan mode is also used. LC-MS analysis was based in the method described by [22].

Table 2 Antimycobacterial activity (MIC and MBC, $\mu \mathrm{g} / \mathrm{ml}$ ) of the 18 plant extracts

\begin{tabular}{|c|c|c|c|c|c|c|c|c|c|c|}
\hline \multirow[t]{2}{*}{ Plant species } & \multirow[t]{2}{*}{ Solvent } & \multirow{2}{*}{$\begin{array}{l}\text { Extraction } \\
\text { Yields (\%) }\end{array}$} & \multicolumn{4}{|c|}{ Minimum inhibitory concentration $(\mu \mathrm{g} / \mathrm{ml})$} & \multicolumn{4}{|c|}{ Minimum bactericidal concentration $(\mu \mathrm{g} / \mathrm{ml})$} \\
\hline & & & H37Rv & H37Ra & Strain 1 & Strain 2 & H37Rv & H37Ra & Strain 1 & Strain 2 \\
\hline \multirow[t]{3}{*}{ Stachy stmolea } & PEF & 0,59 & $>6400$ & $>6400$ & nd & nd & - & - & - & - \\
\hline & EAF & 3,02 & $>6400$ & $>6400$ & nd & nd & - & - & - & - \\
\hline & MEF & 6,52 & $>6400$ & $>6400$ & nd & nd & - & - & - & - \\
\hline \multirow[t]{3}{*}{ Stachys thirkei } & PEF & 0,41 & $>6400$ & $>6400$ & nd & nd & - & - & - & - \\
\hline & EAF & 4,87 & $>6400$ & $>6400$ & nd & nd & - & - & - & - \\
\hline & MEF & 11,21 & $>6400$ & $>6400$ & nd & nd & - & - & - & - \\
\hline \multirow[t]{3}{*}{ Ballota acetabulosa } & PEF & 0,73 & 200 & 400 & 800 & 400 & 800 & 800 & 1600 & 1600 \\
\hline & EAF & 2,30 & $>6400$ & $>6400$ & nd & nd & - & - & - & - \\
\hline & MEF & 8,87 & $>6400$ & $>6400$ & nd & nd & - & - & - & - \\
\hline \multirow[t]{3}{*}{ Thymus sibthorpii } & PEF & 0,61 & 12,5 & 50 & 800 & 400 & 800 & 800 & 800 & 800 \\
\hline & EAF & 3,18 & 12,5 & 12,5 & 400 & 400 & 400 & 400 & 400 & 400 \\
\hline & MEF & 3,85 & 800 & 200 & 1600 & 800 & $>6400$ & $>6400$ & $>6400$ & $>6400$ \\
\hline \multirow[t]{3}{*}{ Satureja aintabensis } & PEF & 0,58 & 25 & 50 & 100 & 100 & 100 & 100 & 100 & 100 \\
\hline & EAF & 3,24 & 12,5 & 12,5 & 50 & 50 & 50 & 50 & 50 & 50 \\
\hline & MEF & 6,39 & 100 & 400 & 3200 & 1600 & $>6400$ & $>6400$ & $>6400$ & $>6400$ \\
\hline \multirow[t]{3}{*}{ Micromeria juliana } & PEF & 0,29 & 1600 & 1600 & - & $n d^{*}$ & $>6400$ & $>6400$ & - & - \\
\hline & EAF & 2,32 & 100 & 50 & 200 & 400 & $>6400$ & $>6400$ & $>6400$ & $>6400$ \\
\hline & PEF & 5,26 & 1600 & 1600 & - & - & $>6400$ & $>6400$ & - & - \\
\hline \multicolumn{11}{|l|}{ Standard drugs } \\
\hline & SM & & 0.63 & 0.63 & 1.25 & 0.63 & - & - & - & - \\
\hline & $\mathrm{INH}$ & & 0.16 & 0.31 & 0.31 & 0.31 & 1.25 & 1.25 & 1.25 & 1.25 \\
\hline & $\mathrm{RIF}$ & & 0.78 & 0.39 & 0.78 & 0.78 & 6.25 & 3.13 & 6.25 & 6.25 \\
\hline & EMB & & 2.73 & 2.73 & 2.73 & 1.37 & - & - & - & - \\
\hline
\end{tabular}

$\mathrm{Nd}$, not determined due to the fact that the samples were not active on H37Rv and H37Ra; nd*: not determined due to insufficient amount of the sample;(-) not tested; PEF, Petroleum ether fraction; EAF, Ethyl acetate fraction; $M E F$, Methanol fraction; SM, Streptomycin; INH, Isoniazid; RIF, Rifampicin; EMB, Ethambutol. 


\section{Stock and working solutions}

For antimycobacterial activity, stock solutions of extracts were prepared in advance at a concentration of $100 \mathrm{mg} /$ $\mathrm{ml}$ in dimethylsulphoxide (DMSO, Merck, Germany) and sterilized by filtration through membrane filter $(\varnothing$ $0.20 \mu \mathrm{m}$; Minisart, Sartorius Bitech, Germany). Stock solutions were kept at $-20^{\circ} \mathrm{C}$ until use. Before the bioassay, working solutions were prepared by diluting stock solutions to four times $(4 \times)$ the maximum desired final testing concentration in sterile Middlebrook 7H9 broth. The final concentration of DMSO in all assays was $\leq 2 \%$, and this was used as a solvent control. It has been shown to be nontoxic for mycobacteria at this concentration.

\section{Anti-tuberculosis drugs}

Isoniazid (INH), rifampicin (RIF), streptomycin (SM), and ethambutol (EMB) (Becton, Dickinson and company, Spark, U.S.A) were used as standards. Stock solutions were prepared in sterile distilled water according to the manufacturer's recommendations.

\section{Mycobacterium strains and growth conditions}

Two well-characterized strains of $M$. tuberculosis were obtained from the American Type Culture Collection (ATCC): M. tuberculosis H37Rv (ATCC 27294) and H37Ra (ATCC 25177), sensitive to all first-line anti-tuberculosis drugs. Two clinical strains namely "strain1" and "strain2" isolated from TB patients were also used. The organisms were maintained on slant of Middlebrook 7H10 agar (Difco, USA) supplemented with $0.5 \%$ glycerol and $10 \%$ OADC (Oleic acid, Albumin, Dextrose, and Catalase; Difco).

\section{Preparation of inoculums for anti-tuberculosis assay}

All strains were grown at $37^{\circ} \mathrm{C}$ in Middlebrook $7 \mathrm{H} 9$ Broth (7H9) (Becton Dickinson), supplemented with $0.2 \% \mathrm{v} / \mathrm{v}$ glycerol (Sigma Chemical Co., St. Louis, MO, USA), and 10\% v/v oleic acid, albumin, dextrose, and catalase (OADC; Becton Dickinson). PANTA 2.5\% (Polymixin, Amphotericin B, Naladixic acid, Trimethoprim and Azlocillin; Becton, Dickinson), an antibiotic supplement, was also added to prevent the growth of any non-mycobacteria.

A suspension was prepared in Middlebrook 7H9 Broth. The turbidity of the suspension was adjusted to the McFarland standard 1.0. The suspension was vortexed for several minutes and allowed to precipitate larger particles then to sit for $20 \mathrm{~min}$. The supernatant was transferred to an empty, sterile tube and allowed to sit for a further 15 min. After being transferred to a new sterile tube, the suspension was adjusted to a 0.5 McFarland turbidity standard by visual comparison. One $\mathrm{ml}$ of the adjusted suspension was diluted in $4 \mathrm{ml}$ of sterile saline.

To prepare inoculum from a positive BACTEC MGIT tube, the positive tubes were used beginning from the day after it first became positive (day 1 positive) up to and including the fifth day (day 5 positive). The positive tubes older than five days were subcultured into fresh growth-medium. The tubes which were day- 1 and day- 2 positive proceeded to the inoculation procedure for the susceptibility test. The tubes between day 3 and day 5 positive were diluted using a $1 \mathrm{ml}$ of the positive broth with $4 \mathrm{ml}$ of sterile saline, the total is 5 , then this diluted suspension were used for inoculation procedures. Inocula prepared from a Day 1 to Day 5 positive MGIT $7 \mathrm{~mL}$ tube range were between $0.8 \times 10^{5}$ to $3.2 \times 10^{5} \mathrm{CFU} / \mathrm{mL}$. Each assay was performed according to the MGIT manual Fluorometric susceptibility test procedure recommended by the manufacturer, Becton, Dickinson and Company [23,24].

\section{Antimycobacterial susceptibility assay}

The activity of all extracts against the aforementioned $M$. tuberculosis strains was tested using the Microplate Presto Blue Assay (MPBA) following the procedure previously described Collins \& Franzblau [25] and modified by Jimenez-Arellanes et al. [26] using Presto blue reagent. Prior to the bioassay, working solutions of the extracts were prepared by diluting stock extract solutions to four times the maximum desired final testing concentration in sterile $7 \mathrm{H} 9$ broth.

\section{The minimal inhibitory concentration (MIC)}

Antimycobacterial susceptibility assay was done according to National Committee for Clinical Laboratory Standards $[24,27]$.

The test was performed in 96-well sterile microplates. All wells received $100 \mu \mathrm{l}$ of supplemented Middlebrook $7 \mathrm{H} 9$ broth. One hundred microliters of a $4 \times$ working solution of 18 plant extracts were added to the first column of each row. Using a multichannel pipette, $100 \mu \mathrm{l}$ was transferred from column 1 to column 2 , and the contents of the wells were mixed well. Identical serial 1:2 dilutions were continued through column 10, and $100 \mu \mathrm{l}$ of excess medium was discarded from the wells in column 10. Then, $100 \mu \mathrm{l}$ of $M$. tuberculosis inoculum was added to the wells in rows $\mathrm{A}$ to $\mathrm{H}$ in columns 1 to 11 . Thus, the wells in columns 11 and 12 served as drug-free controls. Final test concentrations ranges were $6400-12.5 \mu \mathrm{g} / \mathrm{ml}$ in the mixture.

Each microplate was incubated for 5 days at $37^{\circ} \mathrm{C}$. Following incubation, one control growth (well A11) was developed with $20 \mu \mathrm{l}$ of Presto blue solution (Invitrogen, Life Technologies). The plates were re-incubated at $37^{\circ} \mathrm{C}$ for $24 \mathrm{~h}$. After this incubation, if the well remained blue, the reagent would be added to another control well and the result would be read on the following day. If the color turned pink, all the wells in microplate received the Presto blue solutions in the same way and were 
incubated for an additional $24 \mathrm{~h}$ and the colors of all wells recorded. A blue color in the well was interpreted as no growth, and wells with a well-defined pink color were scored as positive for growth. The minimal inhibitory concentration (MIC) was defined as the lowest concentration of sample that prevents a color change to pink. Streptomycin, isoniazid, ethambutol and rifampicin were included as standard drugs. Each experiment was performed in triplicate at least twice.

\section{The minimum bactericidal concentration (MBC)}

In this study, bactericidal activity was determined by microdilution methods as described in our recent publication [28]. Briefly, standard broth dilution technique for MICs was first performing as described above. Then, samples of those dilutions with no visible growth were transferred to new plate prepared with fresh supplemented Middlebrook 7H9 broth. Twenty microliters $(20 \mu \mathrm{l})$ of mycobacterial suspensions were transferred from the former to a new microplate and this was incubated and developed with Presto Blue as for MPBA. The MBC corresponded to the minimum extract concentration that did not cause a color shift in cultures re-incubated in fresh medium $[29,30]$.

\section{Results and discussion}

\section{LC/MS characterization of the phenolic composition of} samples

Standard phenolic, flavonoids and samples were analyzed according to ionization response in ESI mass spectrometry.
Their chromatographic retention time were given in Figure 1, Figure 2 and Table 3.The chemical concentrations $(\mu \mathrm{g} / \mathrm{g})$ of phenolic and flavonoids of the tested plants in PEF, EAF and MEF were given in Table 4.

In the evaluation of the phenolic and flavonoid composition of samples; for MEF extracts of T. sibthorpii; rosmarinic acid, caffeic acid, apigenin 7 glikozide, quercetin, and luteolin were major phenolic compounds in the sort descending. On the other hand, we also determined gallic acid; chlorogenic acid, syringic acid, p-coumaric acid; ferrulic acid, vitexin, naringin, rutin hidrat, oleuropein and naringenin as minor level.

Epicatechin, hesperidine, and trans-cinnamic acid were not detected. In the EAF extracts of T. sibthorpii, rosmarinic acid, luteolin, caffeic acid, naringenin, and quercetin were the major constituents in decreasing concentrations respectively. Gallic acid, p-coumaric,acid and apigenin 7 glycoside were found in less amount. Some of the phenolic and flavonoids such as chlorogenic acid, syringic acid, epicatechin, ferrulic acid, vitexin, naringin, and rutin hidrat were not detected in the EAF extracts of T. sibthorpii.

For S. aintabensis, while the major phenolic compounds were rosmarinic acid, hesperidin, luteolin, caffeic acid, and naringenin for MEF extract in descending order, gallic acid, chlorogenic acid, syringic acid, vitexin, naringin, rutin hidrat, apigenin 7 glycoside, and quercetin were exist in the moderate to less amount. On the other hand, epicatechin, p-coumaric acid, ferrulic acid, and trans-cinnamic acid were not detected.

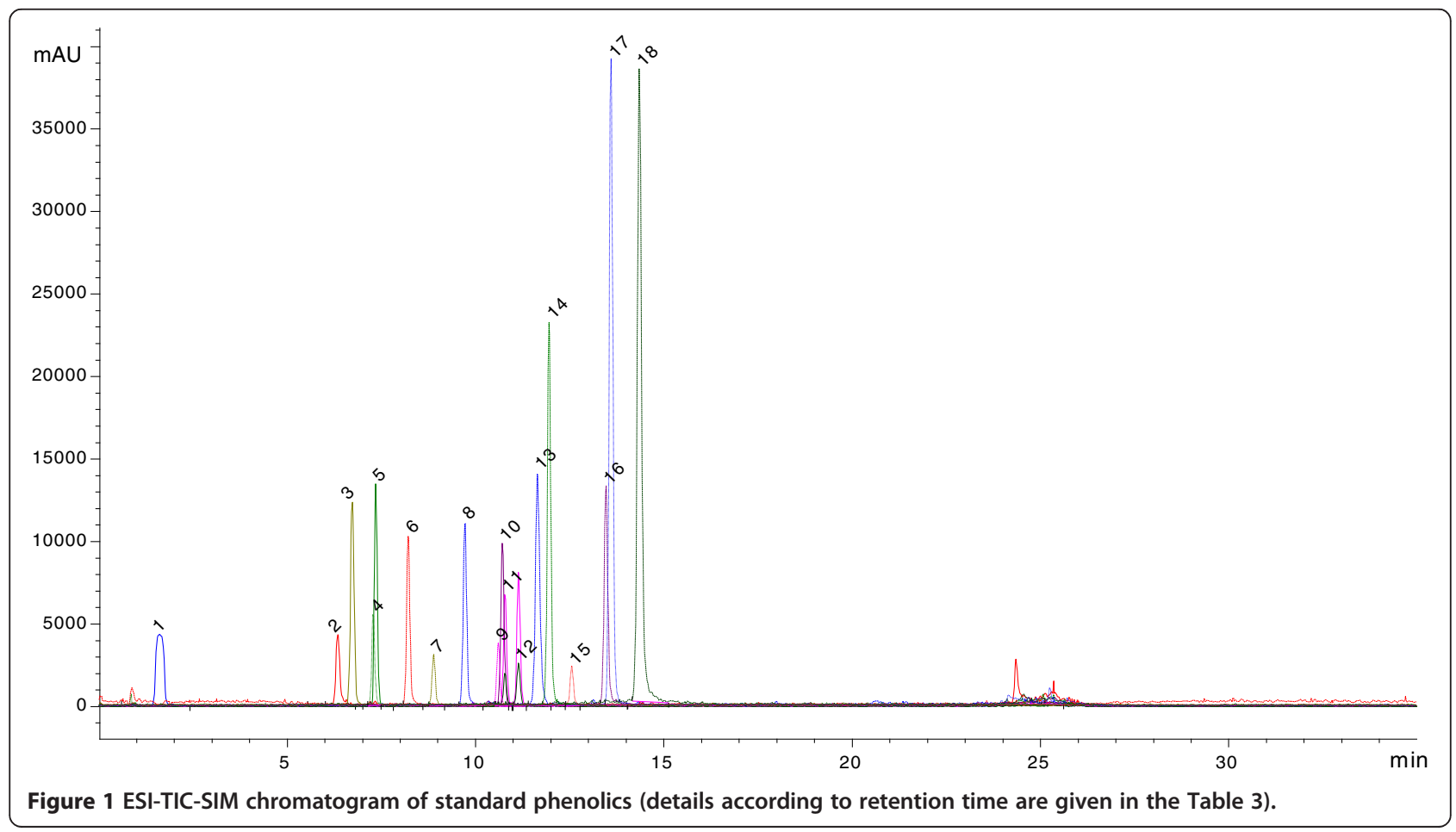




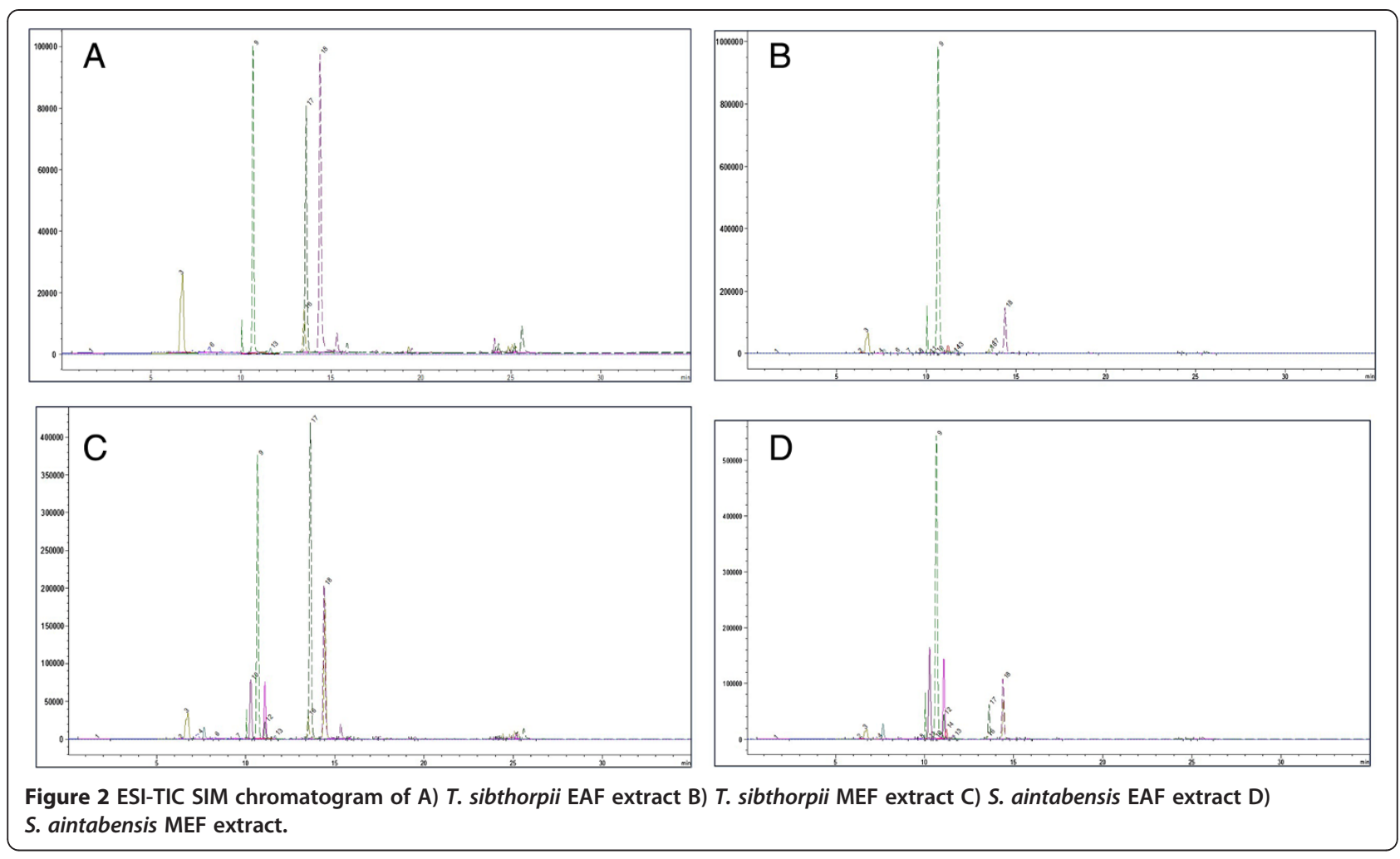

Table 3 LC-MS characteristics of phenolic compounds according to signal no (S.N.), retention times (R.T.) (min), and molecular ions $\left[\mathrm{M}-\mathrm{H}^{+}\right](\mathrm{m} / \mathrm{z})$ at fragment ion $80 \mathrm{eV}$

\begin{tabular}{|c|c|c|c|c|}
\hline S.N. & R.T. & {$\left[\mathrm{M}-\mathrm{H}^{+}\right]$} & Phenolics & Samples \\
\hline 1 & 1,6 & 169 & Gallic acid & $1 \mathrm{~B}, 1 \mathrm{C}, 2 \mathrm{~B}, 2 \mathrm{C}, 3 \mathrm{~B}, 3 \mathrm{C}, 4 \mathrm{~B}, 4 \mathrm{C}, 5 \mathrm{~B}, 5 \mathrm{C}, 6 \mathrm{~B}, 6 \mathrm{C}$, \\
\hline 2 & 6,17 & 353 & Chlorogenic acid & $1 \mathrm{~A}, 1 \mathrm{~B}, 1 \mathrm{C}, 2 \mathrm{~A}, 2 \mathrm{~B}, 2 \mathrm{C}, 3 \mathrm{~A}, 4 \mathrm{~B}, 5 \mathrm{~B}, 5 \mathrm{C}, 6 \mathrm{~B}, 6 \mathrm{C}$ \\
\hline 3 & 6,53 & 179 & Caffeic acid & $1 \mathrm{~B}, 1 \mathrm{C}, 2 \mathrm{~B}, 2 \mathrm{C}, 3 \mathrm{~B}, 3 \mathrm{C}, 4 \mathrm{~B}, 4 \mathrm{C}, 5 \mathrm{~B}, 5 \mathrm{C}, 6 \mathrm{~B}, 6 \mathrm{C}$ \\
\hline 4 & 7,3 & 197 & Syringic acid & $4 C, 2 B, 2 C, 4 B, 5 B, 5 C, 6 B, 6 C$ \\
\hline 5 & 7,34 & 289 & (-)-Epicatechin & $3 C$ \\
\hline 6 & 8,28 & 163 & $\rho$-coumaric acid & $1 B, 1 C, 2 C, 3 B, 3 C, 4 B, 4 C, 5 B, 6 C$ \\
\hline 7 & 8,9 & 193 & Ferrulic acid & $1 C, 2 C, 4 B, 5 B, 6 C$ \\
\hline 8 & 9,72 & 431 & Vitexin & $1 C, 2 B, 2 C, 4 B, 5 B, 6 B, 6 C$ \\
\hline 9 & 10,6 & 359 & Rosmarinic acid & $2 B, 2 C, 3 B, 3 C, 4 B, 4 C, 5 B, 5 C, 6 B, 6 C$ \\
\hline 10 & 10,69 & 579 & Naringin & $1 B, 1 C, 2 B, 2 C, 3 B, 4 B, 5 B, 5 C, 6 B, 6 C$ \\
\hline 11 & 10,76 & 609 & Rutin hidrat & $1 B, 1 C, 2 B, 3 B, 3 C, 4 B, 5 B, 6 B, 6 C$ \\
\hline 12 & 11,12 & 610 & Hesperidine & $1 B, 5 B, 5 C, 6 B, 6 C$ \\
\hline 13 & 11,65 & 431 & Apigenin 7glikozide & $1 B, 1 C, 2 B, 2 C, 3 B, 3 C, 4 B, 4 C, 5 B, 5 C, 6 B, 6 C$ \\
\hline 14 & 11,96 & 539 & Oleuropein & $1 C, 3 C, 4 B, 5 B, 6 B, 6 C$ \\
\hline 15 & 12,57 & 147 & trans-cinnamic acid & \\
\hline 16 & 13,47 & 301 & Quercetin & $1 C, 4 B, 4 C, 5 B, 5 C, 6 B, 6 C$ \\
\hline 17 & 13,613 & 271 & $( \pm)$-Naringenin & $1 B, 1 C, 2 B, 2 C, 3 C, 4 B, 4 C, 5 B, 5 C, 6 C$ \\
\hline 18 & 14,36 & 285 & Luteolin & $1 B, 1 C, 2 B, 2 C, 3 B, 3 C, 4 B, 4 C, 5 B, 5 C, 6 B, 6 C$ \\
\hline
\end{tabular}


Table 4 Chemical concentrations ( $\mu \mathrm{g} / \mathrm{g}$ ) of phenolic of the tested plants in petroleum ether (PEF), ethyl acetate (EAF) and methanol (MEF) extract fractions Plant Extracts Chemical concentrations of phenolic

\begin{tabular}{|c|c|c|c|c|c|c|c|c|c|c|c|c|c|c|c|c|c|c|c|}
\hline \multirow{2}{*}{ No } & & \\
\hline & & 1 & 2 & 3 & 4 & 5 & 6 & 7 & 8 & 9 & 10 & 11 & 12 & 13 & 14 & 1 & 16 & 17 & 18 \\
\hline \multirow{3}{*}{ Stm } & PEF (A) & * & 35,88 & * & * & * & * & $*$ & * & * & * & * & * & $*$ & $*$ & $*$ & * & * & * \\
\hline & MEF (B) & 193,86 & 19821,5 & 1235,31 & * & * & 122,21 & $*$ & $*$ & $*$ & 194,67 & 75,76 & 1690,35 & 5888,53 & * & $*$ & $*$ & 54,01 & 214,67 \\
\hline & $\operatorname{EAF}(\mathrm{C})$ & 504,15 & 371,03 & 3422,58 & 310,78 & $*$ & 666,26 & 257,13 & 206,38 & $*$ & 276,64 & 71,33 & * & 1986,35 & 195,20 & $*$ & 68,44 & 285,56 & 1038,67 \\
\hline \multirow{3}{*}{ Sth } & $\operatorname{PEF}(\mathrm{A})$ & $*$ & 0,81 & * & * & $*$ & $*$ & $*$ & $*$ & $*$ & $*$ & $*$ & $*$ & * & * & $*$ & * & * & * \\
\hline & MEF (B) & 27,02 & 17965,90 & 2092,20 & 363,51 & * & * & $*$ & 276,36 & 460,80 & 202,86 & 80,34 & * & 1851,75 & * & $*$ & * & 66,17 & 233,10 \\
\hline & EAF (C) & 108,31 & 12192,68 & 5208,54 & 1205,07 & * & 200,43 & 257,56 & 263,55 & 1151,40 & 136,21 & $*$ & * & 1255,18 & * & $*$ & * & 121,72 & 465,49 \\
\hline \multirow{2}{*}{$\mathrm{Ba}$} & MEF(B) & 18,45 & 6856,7 & 1567,83 & * & * & 144,04 & $*$ & $*$ & 12258,76 & 301,17 & 120,96 & * & 1104,05 & * & $*$ & * & * & 120,51 \\
\hline & $\operatorname{EAF}(C)$ & 63,11 & 189,34 & 519,04 & * & 330,09 & 160,78 & $*$ & * & 6885,16 & * & 1451,65 & * & 151,11 & 119,81 & $*$ & * & 30,54 & 55,11 \\
\hline \multirow{2}{*}{ Ts } & MEF (B) & 268,9 & 263,86 & 5032,83 & 340,2 & * & 235,97 & 251,6 & 85,24 & 81432,13 & 377,93 & 191,26 & * & 940,27 & 141,95 & $*$ & 645,37 & 452,04 & 3632,13 \\
\hline & $\operatorname{EAF}(C)$ & 39,15 & * & 1908,9 & * & $*$ & 148,3 & $*$ & * & 6074,77 & * & * & * & 97,8 & * & $*$ & 666,37 & 1436,47 & 2390,07 \\
\hline \multirow{3}{*}{ Sa } & MEF (B) & 53,45 & 234,71 & 1383,2 & 443,75 & * & $*$ & $*$ & 106,01 & 42936,05 & 260,38 & 238,73 & 10117,43 & 389,33 & 551,37 & $*$ & 249,27 & 1084,98 & 2446,5 \\
\hline & $\operatorname{EAF}(C)$ & 93,78 & 56,14 & 2587,51 & 956,49 & $*$ & 230,23 & 177,14 & * & 26995,81 & 7748,81 & $*$ & 5633 & 282,47 & * & $*$ & 1518,12 & 7729,86 & 5025,99 \\
\hline & $\operatorname{PEF}(\mathrm{A})$ & $*$ & $*$ & * & * & $*$ & $*$ & $*$ & $*$ & $*$ & $*$ & $*$ & $*$ & $*$ & * & $*$ & $*$ & * & * \\
\hline \multirow[t]{2}{*}{$M j$} & MEF (B) & 76,51 & 5256,91 & 1603,05 & 128,17 & * & $*$ & $*$ & 383,28 & 32457,86 & 581 & 5336,78 & 6013,16 & 480,88 & 201,9 & $*$ & 684,28 & * & 242,2 \\
\hline & EAF (C) & 129,07 & 167,96 & 1434,85 & 215,8 & * & 92,85 & 170,23 & 550,55 & 4449,22 & 60,7 & 679,12 & 734,01 & 92,31 & 34,1 & $*$ & 192,37 & 79,92 & 226,36 \\
\hline
\end{tabular}

Stm: Stachys tmolea; Sth: Stachys thirkei Ba: Ballota acetabulosa Ts:Thymus sibthorpii Sa: Satureja aintabensis Mj:Micromeria juliana;EAF: EthylAcetat; MEF: Methanol; 1; Gallicacid 2; Chlorogenicacid 3; Caffeicacid 4; Syringicacid 5; Epicatechin 6; P-coumaricacid 7; Ferrulicacid 8; Vitexin 9; Rosmarinicacid 10; Naringin 11; RutinHidrat 12; Hesperidine 13; Apigenin 7 Glikozide 14; Oleuropein 15; Trans-cinnamicacid 16; Quercetin 17; Naringenin 18; Luteolin, ${ }^{*}$ : Not detected 
In EAF extract of $S$. aintabensis; rosmarinic acid has the highest concentration. It is followed by naringin, naringenin, hesperidine, caffeic acid, and quercetin. The lesser quantity of substances were gallic acid, chlorogenic acid, syringic acid, p-coumaric acid, ferrulic acid, and apigenin 7 glycoside. Some of the phenolic and flavonoids such as epicatechin, vitexin, rutin hidrat, oleuropein, and transcinnamic acid were not found.

For others, the major phenolic compounds for $M$. juliana were rosmarinic acid, chlorogenic acid, rutin hydrate and caffeic acid in the MEF extract. The major phenolic compound for EAF and MEF extracts of B. acetabulosa was chlorogenic acid.

The major phenolic compounds for $S$. thirkei were chlorogenic acid, caffeic acid, ferulic acid, and rosmarinic acid for EAH extract; chlorogenic acid and caffeic acid for MEF extract. For S. tmolea the major phenolic compound for EAF was caffeic acid.

The determination of oleuropein in some extracts of plants such as EAF of $S$ tmolea and B. acetabulosa; MEF of T. sibthorpii and S. aintabensis; and also EAF and MEF of $M$. juliana was one of the interesting and amazing results for us. Because oleuropein which may have a role in different mechanisms such as antioxidant, signaling mecanism or decreased rates of cancer, commonly presented as related with olive leaves which is high amounts in olive leaves such as 60-90 mg/g of dry matter [31] but only little in olive oil [32].

\section{Antimycobacterial activity}

In this study, LC-MS revealed large quantity of rosmarinic acid in all EAF and MEF extracts that showed antimycobacterial activity: T. sibthorpii, S. aintabensis, M. juliana. Many studies have suggested that high level of rosmarinic acid might be associated with antimycobacterial activity [21]. Many biological activities have been described for rosmarinic acid, of which the main ones are: astringent, antioxidative, anti-inflammatory, antimutagen, antibacterial and antiviral [33]. The latter activity is used in the therapy of Herpes simplex infections, with extracts of Melissa officinalis containing rosmarinic acid.

As many different methods are available to evaluate anti-tuberculosis activity, no specific cut-off value has yet been established for the anti-tuberculosis activity of plant extracts. In previous studies, plants extracts were considered active against $M$. tuberculosis and other related Mycobacterium strains if MIC was $\leq 100 \mu \mathrm{g} / \mathrm{ml}[34] ; \leq 125$ $\mu \mathrm{g} / \mathrm{ml}[35] ; \leq 200 \mu \mathrm{g} / \mathrm{ml}[26,36] ; \leq 500 \mu \mathrm{g} / \mathrm{ml}$ [37]; $\leq 1600$ $\mu \mathrm{g} / \mathrm{ml}[38]$; and $\leq 2048 \mu \mathrm{g} / \mathrm{ml}$ [28]. Other studies considered other quantifiable inhibitions as indication of activity $[21,39]$. In this study, we interpreted activity as inhibition at any values of $\mathrm{MIC} \leq 6400 \mu \mathrm{g} / \mathrm{ml}$, the highest test concentration. Plant extracts that did not exhibit inhibition at up to $6400 \mu \mathrm{g} / \mathrm{ml}$ were considered inactive. However, activity was classified as significant if $\mathrm{MIC}<100 \mu \mathrm{g} / \mathrm{ml}$, moderate if $100<\mathrm{MIC} \leq 625 \mu \mathrm{g} / \mathrm{ml}$ or weak if $\mathrm{MIC}>625$ $\mu \mathrm{g} / \mathrm{ml}$.

Eighteen crude extracts from 6 Turkish plant species of the family Lamiaceae were obtained by successive extraction with three solvents of varying polarity.

The result showed that methanol gave highest yield of extract compared to petroleum ether and ethyl acetate extraction; the yield from petroleum ether was very low (Table 2).

M. tuberculosis H37Rv ATCC 27294 and M. tuberculosis H37Ra ATCC 25177 variants were used as target organisms in the preliminary assays; all plant extracts that exhibited activity were further tested against two clinical strains (strain 1 and strain 2). The results are shown in Table 2 .

Our rationale for using $\mathrm{H} 37 \mathrm{Rv}$ (ATCC 27294) and H37Ra (ATCC 25177) was that they have drug susceptibility profiles that are reasonably representative of the majority of drug-susceptible clinical isolates [40]; In addition, they are used around the world as a standard, and could provide an opportunity to identify new compounds effective against strains of $M$. tuberculosis. These results showed that 10 of 18 extracts obtained from three solvents tested, exhibited anti-tuberculosis activity against all the tested M. tuberculosis strains, with MICs in the range 12.5-1600 $\mu \mathrm{g} / \mathrm{ml}$ and MBC $50-1600 \mu \mathrm{g} / \mathrm{ml}$. Out of these, according to the classification used [41]: The three fractions of $S$. aintabensis exhibited significant activity. The PEF and EAF of $S$. aintabensis exhibited the most potent activity against all the tested mycobacteria, with MICs value of $12.5-100 \mu \mathrm{g} / \mathrm{ml}$, while the activity of its MEF was significant against $M$. tuberculosis $\mathrm{H} 37 \mathrm{Rv}$ (MIC $100 \mu \mathrm{g} / \mathrm{ml}$, moderate against H37Ra (MIC $400 \mu \mathrm{g} / \mathrm{ml}$ ) and weak against the two clinical strains. PEF and EAF of $S$. aintabensis not only inhibited the growth of mycobacteria, but also showed bactericidal effect, with MBC value of 50 and 100 $\mu \mathrm{g} / \mathrm{ml}$ against all the tested organisms. It is known that phenolics are effective antimicrobial agents against a wide array of microorganisms [42]. The strong antimycobacterial properties of $S$. aintabensis observed in the present study could be due to the presence of phenolic compounds such as rosmarinic acid, naringenin, hesperidin, luteolin and caffeic acid. This is the first study of the antituberculosis activity and chemical composition of $S$. aintabensis. Antimycobacterial activity of S. aintabensis was not previously reported.

The two fractions of T. sibthorpii, PEF and EAF, exhibited significant activity against $\mathrm{H} 37 \mathrm{Rv}$ and $\mathrm{H} 37 \mathrm{Ra}$ with MICs value of $12.5-50 \mu \mathrm{g} / \mathrm{ml}$; and moderate activity against the two clinical strains (MIC $400 \mu \mathrm{g} / \mathrm{ml}$ ). The MEF of $T$. sibthorpii exhibited moderate activity against H37Ra (MIC $200 \mu \mathrm{g} / \mathrm{ml}$ ) and weak activity against the three others strains $(800$ and $1600 \mu \mathrm{g} / \mathrm{ml})$. The PEF and 
EAF of T. sibthorpii also showed bactericidal effect against all the tested respectively Mycobacteria, with $\mathrm{MBC}$ values of 400 and $800 \mu \mathrm{g} / \mathrm{ml}$.

The good antimycobacterial properties of $T$. sibthorpii could depend on the presence of phenolic compounds such as rosmarinic acid and caffeic acid. T. sibthorpii was previously screened for its antimicrobial activity, and its ethanol extract was reported to show broad antimicrobial activity spectrum. Recent studies have shown that Thymus species have strong antibacterial, antifungal [43], antiviral and expectorating [44], activities, but no data on its antimycobacterial activity seem to have been published previously.

The PEF of B. acetabulosa presented moderate activity against H37Rv, H37Ra and clinical strain 1 (MIC 200$400 \mu \mathrm{g} / \mathrm{ml}$ ), and weak activity against clinical strain 2 (MIC $800 \mu \mathrm{g} / \mathrm{ml}$ ). This extract was also bactericidal, with $\mathrm{MBC}$ value of $800 \mu \mathrm{g} / \mathrm{ml}$ against $\mathrm{H} 37 \mathrm{Rv}$ and H37Ra and $1600 \mu \mathrm{g} / \mathrm{ml}$ against the two clinical strains. The EAF and MEF of $B$. acetabulosa did not show any activity against the tested strain Plants of this genus have been traditionally used to treat nausea, vomiting, nervous dyspepsia, and also are used for their antiemetic, sedative, antibacterial and mild astringent properties [45]. Aerial parts of the plant are used internally to treat inflammation, to suppress cough and against gastrointestinal disorders [46]. The antibacterial and antifungal activities of B. acetabulosa were reported by Dulger and Sener [46]. The antioxidant activity of $B$. acetabulosa has been reported [10], but to the best of our knowledge, the antimycobacterial properties have not been reported previously.

The EAF of $M$. juliana showed a most potent activity with the minimal inhibitory concentration (MIC) value of 100 and $50 \mu \mathrm{g} / \mathrm{ml}$, while the corresponding PEF and MEF exhibited very weak activity (MIC $1600 \mu \mathrm{g} / \mathrm{ml}$ each). $M$. Juliana extracts have no bactericidal effect. The antimycobacterial activity exhibited by $M$. juliana probably depends on the quantity of phenolics such as rosmarinic acid, chlorogenic acid, rutin hydrate and caffeic acid.

It is also noticeable that all plant extracts containing high levels of chlorogenic acid were inactive or showed very weak activity against the strain of $M$. tuberculosis. This is the case for MEF of M. juliana, MEF of B. acetabulosa, MEF and EAF of $S$. thirkei, and EAF of $S$. tmolea.

The large amount of chlorogenic acid could react as an antagonist to inhibit the activity of other compounds like rosmarinic acid. When the composition of $T$. sibthorpii and $S$. aintabensis extracts are compared to M. Juliana extract, the three plants contain a large amount of rosmarinic acid, however, T. sibthorpii and S. aintabensis contain very low levels of chlorogenic acid, whereas $M$. juliana is very rich in chlorogenic acid.

The two Stachys species (S. tmolea and S. thirkei) showed no activity against the screened strains in our assays. Essential oil from S. tmolea was investigated by disk diffusion method on C. albicans by Goren et al. (2011) [47] and was reported to show antifungal activity. To the best of our knowledge, the above-mentioned antifungal activity was the only previous reported activity on S. tmolea. Regarding S. thirkei, no activity has been evaluated until now.

The finding that the major phenolic compound of $S$. tmolea and S. thirkei is chlorogenic acid could partially explain their inactivity against $M$. tuberculosis.

In this study, we reported that PEF and EAF were most active compared to the methanol fraction. This might be because the mycobacteria, having a very lipidrich hydrophobic cell-wall, are often more susceptible to compounds with weaker polarity [48].

\section{Conclusion}

Tuberculosis is a very serious disease in the world. A total of 1.4 million people died from TB in 2011. One third of the world's population, especially from low- and middleincome countries, is infected with Mycobacterium tuberculosis. In addition, approximately one in four deaths among people with HIV is due to TB. MDR-TB, affecting 630,000 people in the world, is caused by inappropriate use of TBdrugs, does not respond to standard treatments because it is costly and ineffective to treat [49].

In the present investigation, we also demonstrated for the first time the efficacy of the PEF and EAF of two plant species, S. aintabensis and T. sibthorpii. In addition, PEF extract of Ballota acetabulosa was also efficient against $M$. tuberculosis strains including isolates taken from patients. These extracts displayed very high activity, not only by inhibiting but also by killing all of the Mycobacteria strains. The phenolics and flavonoids might represent promising sources of anti-TB drugs. The LC-MS spectra of all the extracts revealed their main phenolic composition, which was closely associated with the observed antimycobacterial activity [50]. However, advanced research will be necessary to confirm this hypothesis.

Consequently, compounds in the extracts and potential activity may guide the future isolation and antimycobacterial evaluation of the active principles. Further phytochemical and pharmacological studies of these plants are clearly worthwhile. Flavonoids might be "a modal" for the drug design. Identification of the antimycobacterial mechanism of action might be the key to the development of these compounds.

\section{Abbreviations}

TB: Tuberculosis; MDR: Multi-drug resistance; SLD: Second-line drug; DOTS: Directly observed treatment short course; HIV: Human

immunodeficiency virus; Rt: Retention time; ATCC: American type culture collection; OADC: Oleic acid albumin, dextrose, and catalase;

PANTA: Polymixin amphotericin B, naladixic acid, trimethoprim and azlocillin; MGIT: Mycobacteria growth indicator tube; BACTEC: Battle area clearance training, equipment and consultancy; INH: Isoniazid; RIF: Rifampicin; 
SM: Streptomycin; EMB: Ethambutol; DMSO: Dimethyl-sulphoxide; ESI: Electrospray ionisation; $\mathrm{MeOH}$ : Methanol; PEF: Petroleum ether fraction; EAF: Ethyl acetate fraction; MEF: Methanol fraction; AST: Antimicrobial susceptibility testing; MIC: Minimal inhibitory concentration; MBC: Minimal bactericide concentration; LC-MS: Liquid chromatography-mass spectrometry; MPBA: Microplate prestoblue alamar assay; ESI: Electrospray ionisation; TIC: Total ion current; SIM: Selected ion monitoring.

\section{Competing interest}

The authors declare that they have no competing interest.

\section{Authors' contributions}

EMT carried out the experimental part such as preparation of plant extracts, preparation of inoculums, evaluation of antimycobacterial activity, preparation of sample for LC-MS and manuscript writing. TA provided the mycobacteria strains, supervised the work, evaluated the results and corrected the manuscript for publication. FS provided some plants and corrected the manuscript for publication. SM contributed to antimycobacterial evaluation and LC-MS analysis. HA contributed to LC-MS analysis. All authors read and approved the final manuscript.

\section{Acknowledgements}

Emmanuel Mouafo Tekwu is very grateful to TUBITAK (2216) for travel grant and living allowance at the Balikesir University, Balikesir, Turkey. The authors are grateful to Mrs. Sema CARIKCl, who kindly provided laboratory facilities for the extraction; Ayhan Aysal, for assistance in LC-MS analyses; and Professor Gulendam Tumen, who identified the plant specimens.

Received: 14 September 2013 Accepted: 13 December 2013 Published: 21 December 2013

\section{References}

1. Dye C, Scheele S, Dolin P, Pathania V, Raviglione MC: Consensus statement. Global burdenof tuberculosis: estimated incidence, prevalence, and mortality by country. WHO global surveillance and monitoring project. J Americ Med Ass 1999, 282:677-686.

2. Harley RM, Atkins S, Budantsev A, Cantino PD, Conn BJ, Grayer R, Harley MM, De Kok R, Krestovskaja T, Morales R, et al: Labiatae. In The Families and Genera of Vascular Plants, vol 7. Edited by Kubitzki K. Berlin: Springer Verlag, Berlin, Volume 7; 2004:167-275.

3. Baser KHC: Essential oils of Anatolian Labiatae:a profile. Acta Hortic 1993, 333:217-238.

4. Ozturk M, Duru ME, Aydogmus-Ozturk F, Harmandar M, Mahlicli M, Kolak U, Ulubelen A: GC-MS analysis and antimicrobial activity of essential oil of Stachys cretica subsp. smyrnaea. Nat Prod Commun 2009, 4:109-114.

5. Grujic-Jovanovic S, Helen D, Marin P, Sokovic M: Composition andantimicrobial activity of the essential oil of six Stachys species from Serbia. Flav Fragr J 2004, 19:139-144.

6. Amirghofran Z, Bahmani M, Azadmehr A, Javidnia K: Anticancer effects of various Iranian native medicinal plants on human tumor cell lines. Neoplasma 2006, 53(5):428-433.

7. Erdemoglu N, Turan NN, Cakici I, Sener B, Aydin A: Antioxidant activities of some Lamiaceae plant extracts. Phytother Res 2006, 20(1):9-13.

8. Papageorgio V: GLC-MS Computer analysis of the essential oil of Thymus capitatus. Planta Medica 1980, 24:29-33. Supplement.

9. Davis PH: Flora of Turkey and the East Aegean islands, Volume 7. Edinburgh: Edinburgh University Press; 1982.

10. Citoglu GS, Çoban T, Sever BI, Scan M: Antioxidant properties of Ballota species growing in Turkey. J Ethnopharmacol 2004, 92:275-280.

11. Vokou D, Katradi K, Kokkini S: Ethnobotanical survey of Zagori (Epirus, Greece), a renowned centre of folk medicine in the past. J Ethnopharmacol 1993, 39(3):187-196.

12. Askun T, Tumen G, Satil F, Kilic T: Effects of some lamiaceae species methanol extracts on potential mycotoxin producer fungi. Pharm Biol 2008, 46:688-694.

13. de Oliveira TL, de Araújo SR, Ramos EM, das Graças Cardoso M, Alves E, Piccoli RH: Antimicrobial activity of Satureja montana L. essential oil against Clostridium perfringens type $A$ inoculated in mortadella-type sausages formulated with different levels of sodium nitrite. Int J Food Microbiol 2011, 144(3):546-555.
14. Öztürk M: Anticholinesterase and antioxidant activities of Savoury (Satureja thymbra L.) with identified major terpenes of the essential oil. Food Chem 2012, 134:48-54.

15. Yamasaki K, Nakano M, Kawahata T, Mori H, Otake T, Ueba N: Anti HIV-1 activity of herbs in Labiatae. Biol Pharm Bull 1998, 21:829-833.

16. Newton SM, Lau C, Wright CW: A review of antimycobacterial natural products. Phytother Res 2000, 14(5):303-322.

17. Newman DJ, Cragg GM: Natural products as sources of new drugs over the last 25 years. J Nat Prod 2007, 70:461-477.

18. Xu H-X, Wan M, Dong H, But PP-H, Foo LY: Inhibitory activity of 488 flavonoids and tannins against HIV-1 protease. Biol Pharm Bull 2000, 23:1072-1076.

19. Xu H-X, Lee SF: Activity of plant flavonoids against antibiotic-resistant 490 bacteria. Phytother Res 2001, 15:39-43.

20. Tosun F, Akyüz Kizilay Ç, Sener B, Vural M: The evaluation of plants from Turkey for in vitro antimycobacterial activity. Pharm Biol 2005, 43:58-63.

21. Askun T, Tumen G, Satil F, Ates M: Characterization of the phenolic composition and antimicrobial activities of Turkish medicinal plants. Pharm Biol 2009, 47(7):563-571.

22. Perez-Magarino S, Revilla I, Gonzalez-SanJose ML, Beltran S: Various applications of liquid chromatography-mass spectrometry to the analysis of phenolic compounds. J chromatography A 1999, 847(1-2):75-81.

23. BD: Becton, Dickinson and company newsletter BD Bactec MGIT 960 SIRE kit now FDA-cleared for susceptibility testing of Mycobacterium tuberculosis. Microbiology News \& Ideas 2002, 13:4-4.

24. National Committee for Clinical Laboratory Standards: Susceptibility Testing of Mycobacteria, Nocardiae, and Other Aerobic Actinomycetes; Approved Standard, vol 23, No 18. USA: NCCLS document M24-A [ISBN 1-56238-500-3]; 2003.

25. Collins L, Franzblau SG: Microplate alamar blue assay versus BACTEC 460 system for high-throughput screening of compounds against Mycobacterium tuberculosis and Mycobacterium avium. Antimicrob Agents Chemother 1997, 41:1004-1009.

26. Jimenez-Arellanes A, Meckes M, Ramirez R, Torres J, Luna-Herrera J: Activity against multidrug-resistant Mycobacterium tuberculosis in Mexican plants used to treat respiratory diseases. Phytother Res 2003, 17(8):903-908.

27. National Committee for Clinical Laboratory Standards: Methods for Dilution Antimicrobial Susceptibility Tests for Bacteria That Grow Aerobically; Approved Standard - Seventh Edition. NCCLS Document M7-A7; vol 26, No 2. 2006.

28. Tekwu EM, Askun T, Kuete V, Nkengfack AE, Nyasse B, Etoa FX, Beng VP: Antibacterial activity of selected Cameroonian dietary spices ethno-medically used against strains of Mycobacterium tuberculosis. J Ethnopharmacol 2012, 142(2):374-382.

29. Battu GR, Kumar BM: Phytochemical and antimicrobial activity of leaf extract of asparagus racemosus Willd. Pharmacognosy $J 2010$, 2(12):456-463.

30. Omar SH: Oleuropein in olive and its pharmacological effects. Scientia Pharmaceutica 2010, 78:133-154.

31. Japon-Lujan R, Luque de Castro MD: Liquid-liquid extraction for the enrichment of edible oils with phenols from olive leaf extracts. J Agric Food Chem 2008, 56(7):2505-2511.

32. Bontempo P, Carafa V, Grassi R, Basile A, Tenore GC, Formisano C, Rigano D, Altucci L: Antioxidant, antimicrobial and anti-proliferative activities of Solanum tuberosum L. var. vitelotte. Food Chem Toxicol 2013, 55:304-312.

33. Parnham MJ, Kesselring K: Rosmarinic acid. Drugs Future 1985, 10:756-757.

34. Gordien AY, Gray Al, Ingleby K, Franzblau SG, Seidel V: Activity of scottish plant, lichen and fungal endophyte extracts against Mycobacterium aurum and Mycobacterium tuberculosis. Phytother Res 2010, 24(5):692-698.

35. Molina-Salinas GM, Pérez-López A, Becerril-Montes P, Salazar-Aranda R, Said-Fernández S, Torres NWD: Evaluation of the flora of Northern Mexico for in vitro antimicrobial and antituberculosis activity. J Ethnopharmacol 2007, 109(3):435-441.

36. MdR C-C, Ramirez-Cabrera MA, Santiago OG, Garza-Gonzalez E, Palacios IDP, Luna-Herrera J: Activity against drug resistant-tuberculosis strains of plants used in Mexican traditional medicine to treat tuberculosis and other respiratory diseases. Phytother Res 2008, 22(1):82-85.

37. Newton SM, Lau C, Gurcha SS, Besra GS, Wright CW: The evaluation of forty-three plant species for in vitro antimycobacterial activities; isolation of active constituents from Psoralea corylifolia and Sanguinaria canadensis. J Ethnopharmacol 2002, 79(1):57-67. 
38. Mohamad S, Zin NM, Wahab HA, Ibrahim P, Sulaiman SF, Zahariluddin ASM, Noor SSM: Antituberculosis potential of some ethnobotanically selected Malaysian plants. J Ethnopharmacol 2011, 133(3):1021-1026.

39. Mativandlela SPN, Meyer JJM, Hussein AA, Houghton PJ, Hamilton CJ, Lall N: Activity against Mycobacterium smegmatis and $M$. tuberculosis by extract of South African medicinal plants. Phytother Res 2008, 22(6):841-845.

40. Pauli GF, Case RJ, Inui T, Wang Y, Cho S, Fischer NH, Franzblau SG: New perspectives on natural products in TB drug research. Life SC Natureceuticals (Natural Products), Nutraceuticals, Herb Bot Psychoactives: Drug Discovery Drug-drug Interactions - Volume I: Natureceuticals (Natural Products), Herb Bot, Psychoactive Hallucinogens Related Prod 2005, 78(5):485-494.

41. Kuete V: Potential of cameroonian plants and derived products against microbial infections: a review. Planta Medica 2010, 76:1479-1491.

42. Cowan MM: Plant products as antimicrobial agents. Clin Microbiol Rev 1999, 12:564-582.

43. Karaman S, Digrak M, Ravid U, Ilcim A: Antibacterial and antifungal activity of the essential oils of Thymus revolutus Celak from Turkey. $J$ Ethnopharmacol 2001, 76:183-186.

44. Brasseur T: Etudes botaniques, phytochimiques et pharmacologiques consacrees au Thym. J Pharm Belg 1983, 38:261-272.

45. Newall CA, Anderson LA, Philipson JD: Herbal medicines, a guide for health-care professionals. London: The Pharmaceutical Press; 1996.

46. Dulger B, Sener A: Evaluation of antimicrobial activity of Ballota acetabulosa. Afr J Microbiol Res 2010, 4:1235-1238.

47. Goren AC, Piozzi F, Akcicek E, Kihc T, CÇarkıcı S, Mozioğlu E, Setzer WN: Essential oil composition of twenty-two Stachys species (mountain tea) and their biological activities. Phytochem Lett 2011, 4:448-453.

48. Connell ND, Nikaido H: In Tuberculosis: Pathogenesis, Protection and Control. Edited by Bloom BR. Washington, D.C: ASM Press; 1994:333-352

49. World Health Organization: Global tuberculosis report 2012, World Health Statistics, WHO report 2012. Geneva Switzerland: WHO; 2012.

50. Duarte J, Perez-Palencia R, Vargas F, Ocete MA, Perez-Vizcaino F, Zarzuelo A, Tamargo J: Antihypertensive effects of flavonoid quercetin in spontaneously hypertensive rats. Bras J Pharmacol 2001, 113:117-124.

doi:10.1186/1472-6882-13-365

Cite this article as: Askun et al: Preliminary antimycobacterial study on selected Turkish plants (Lamiaceae) against Mycobacterium tuberculosis and search for some phenolic constituents. BMC Complementary and Alternative Medicine 2013 13:365.

\section{Submit your next manuscript to BioMed Central and take full advantage of:}

- Convenient online submission

- Thorough peer review

- No space constraints or color figure charges

- Immediate publication on acceptance

- Inclusion in PubMed, CAS, Scopus and Google Scholar

- Research which is freely available for redistribution 